\title{
Predictive testing for hereditary breast and ovarian cancer: a psychological framework for pre-test counselling
}

\author{
Marleen Decruyenaere ${ }^{1}$, Gerry Evers-Kiebooms ${ }^{1}$, Lieve Denayer ${ }^{1}$, Myriam Welkenhuysen $^{1}$, \\ Erna Claes ${ }^{1}$, Eric Legius ${ }^{1}$ and Koen Demyttenaere ${ }^{2}$
}

${ }^{1}$ Centre for Human Genetics and ${ }^{2}$ Department of Psychiatry, University of Leuven, Leuven, Belgium

\begin{abstract}
Since the identification of two breast-ovarian cancer susceptibility genes (BRCA1/2), predictive testing for hereditary breast/ ovarian cancer (HBOC) has been available. Given the complexity and uncertainties of HBOC and the potential impact of predictive testing on psychological well-being, we offer the test applicants a combination of information-oriented and psychological counselling. In this paper, we describe the multidisciplinary approach for predictive testing for HBOC as a clinical service in Leuven, hereby focusing on psychological and decision counselling practice. Attention is paid to the theoretical framework used for pre-test psychological counselling in Leuven. We discuss three important interacting dimensions of psychological counselling: individual emotional support, decision counselling and support of the family communication process. Decision counselling consists of an evaluation of the cognitive and the emotional processing of the information given and strategies and resources for coping. This serves as a starting point to facilitate free informed decision making. Scenario development is used as a decision aid. European Journal of Human Genetics (2000) 8, 130-136.
\end{abstract}

Keywords: Hereditary breast and ovarian cancer; BRCA1; BRCA2; predictive testing; genetic counselling; psychological aspects

\section{Introduction}

The lifetime risk for women in industrialised countries to contract breast cancer is estimated to be $10-12 \% .{ }^{1,2}$ Based on the Belgian National Cancer Registry, the cumulative incidence for Belgian women to contract breast cancer is estimated to be $7 \%$ before the age of 75 . It is estimated that about $5-10 \%$ of breast and ovarian cancers might result from a genetic predisposition. ${ }^{3} \mathrm{~A}$ large proportion of the hereditary breast and ovarian cancers can be attributed to a BRCA1 mutation on chromosome $17^{4}$ or to a BRCA2 mutation on chromosome $13 .{ }^{5}$ However, the penetrance of these BRCA1 and BRCA2 mutations is uncertain and variable. ${ }^{6-9}$ Women who have inherited a mutant BRCA1 or BRCA2 allele have a cumulative risk of $50-80 \%$ to develop breast cancer before

Correspondence: Professor Dr G Evers-Kiebooms, Centre for Human Genetics, U.Z. Gasthuisberg, Herestraat 49, B-3000 Leuven, Belgium. Tel: +3216345867; Fax: +3216346051;

E-mail: gerry.kiebooms@med.kuleuven.ac.be

Received 2 February 1999; revised 28 September 1999; accepted 15

October 1999 age 70. The lifetime risk of BRCA 1 mutation carriers developing ovarian cancer is about $20-60 \%$ and for BRCA2 mutation carriers about $10-30 \%$. BRCA1 mutation carriers have a risk of about $6 \%$ of developing colon cancer and of about $8 \%$ of developing prostate cancer before the age of 70 . Male BRCA2 mutation carriers have a cumulative risk for breast cancer, estimated to be $6 \%$ by age 70 . The penetrance estimates must always be used with caution. They are appropriate for counselling in multiple-case families but may not apply to mutation carriers in every family. ${ }^{9}$

Cancer threatens and causes psychological distress. Breast and ovarian cancers are particularly threatening for a woman's self-esteem and body image because they concern parts of the female body connected with fertility, femininity and sexuality. ${ }^{10,11}$ Moreover, hereditary breast and ovarian cancer ( $\mathrm{HBOC})$ is associated with many threatening uncertainties: ${ }^{12-14}$ the risk of being a mutation carrier; the incomplete penetrance among mutation carriers; the influence of other genes and of biological and environmental factors such as hormones and nutrition; the uncertain efficacy of early 
detection methods, prophylactic surgery and chemo-prevention; the issue of treatment and prognosis of HBOC. For 5 years, predictive testing has increasingly been offered to persons with a family history of breast/ovarian cancer. Given the complexity and uncertainties of $\mathrm{HBOC}$ and the potential impact of test results on anxiety, depression levels and selfesteem, it has been recommended ${ }^{15-20}$ that predictive testing should be undertaken by a multidisciplinary team. Test participants need fully to understand what the results of the predictive test may mean for them before the test is performed. They should receive appropriate information and support before and after predictive testing. Research protocols and follow-up studies have been set up all over the world to evaluate the efficacy and long-term impact of predictive testing for $\mathrm{HBOC}$.

In Leuven, genetic testing for $\mathrm{HBOC}$ has been available as a clinical service since the end of 1997. It is the aim of the present paper to describe the multidisciplinary predictive testing service for $\mathrm{HBOC}$ in our centre, thereby focusing on the psychological framework at the start of pre-test psychological and decision counselling.

\section{Predictive testing for $\mathrm{HBOC}$ in Leuven}

In Leuven, the genetic testing team for $\mathrm{HBOC}$ consists of a clinical geneticist, a social nurse, a psychologist (staff of the Centre for Human Genetics) and a number of medical specialists at the University Hospital of Leuven (oncologist, gynaecologist, surgeon, psychiatrist, etc.). In this paper, we describe the predictive test service for asymptomatic persons from a family in which a BRCA1/2 mutation has been detected (Table1). The genetic testing of affected persons is the topic of continuing retrospective study.

\section{First counselling session: medical/educational counselling and emotional support}

The individuals to be tested receive accurate and balanced information and education about genetics in general, HBOC and its heritability, cancer risks, the predictive test and its implications, the alternatives to prevention and early detection and the benefits and limitations of these alternatives. This information and education phase isintended to increase the participant's knowledge and understanding of genetic testing for $\mathrm{HBOC}$ and its implications. Discussion of the family history of cancer during this session generally triggers negative emotions (grief, anxiety, depression, unresolved loss). Alleviation and management of these emotions are very important. Because of the complexity and the uncertainty associated with $\mathrm{HBOC}$, this session is intensive and time-consuming.

After the first session, the test participants receive an educational leaflet that summarises the information given. An outline of the predictive test programme, including the post-test follow-up, and the address and tel ephone number of the genetic centre are also provided. This information is
Table 1 Outline of the predictive test protocol for $\mathrm{HBOC}^{1}$

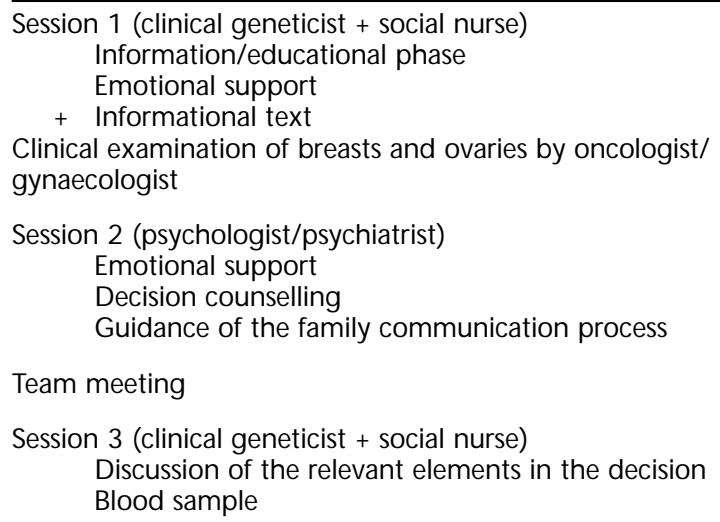

Communication of the result (clinical geneticist + social nurse)

Medical follow-up (oncologist/gynaecologist)

For mutations carriers

Regular screening for early detection or

Preventive surgery (preceded by a consultation with psychologist and psychiatrist)

For non-carriers

Screening for early detection according to general population level recommendations

Psychological follow-up (social nurse + psychologist)

For mutation carriers and non-carriers: After 1 month, 1 year and 5 years

${ }^{1}$ For asymptomatic persons of a family in which the BRCA1/2 mutation has been identified.

not only for personal use but can be distributed to other relatives to inform them about $\mathrm{HBOC}$ and the predictive test.

\section{Second counselling session: psychological counselling}

Psychological counselling is conducted by a psychologist and perhaps a psychiatrist. The psychiatrist is a member of the Institute for Familial and Sexuological Sciences. The major objectives of the second session are to: provide individual emotional support; facilitate the decision making process; and discuss family communication. The decision counselling includes an evaluation of the test participant's cognitive and emotional processing of the information given and their strategies and resources for coping. A helpful method in decision counselling is the development of 'scenarios'. ${ }^{21}$ This means that we ask the test participants to explore the possible outcomes of predictive testing as well as the consequences of declining the test. They are asked to anticipate what could happen in each situation and how they would react in behaviour and emotionally. In this we pay special attention to the expected effect of the test result on specific areas: individual psychological functioning (including body image), the partner relationship (including sexual relationship), family planning, adherence to early detection procedures, timing of preventive measures and 
relationships with other family members. Scenario development facilitates the decision making by structuring the problems of making decisions and by stimulating the expression of beliefs, experiences, emotions, motivations and values, taking into account the social context. It enhances feelings of personal control by preparing the test participant to cope behaviourally and emotionally with the test result. At this stage, it is important to identify any lack of social support and inappropriate coping strategies, such as denial or hypervigilance. Reduction of extreme levels of anxiety by cognitive intervention may be appropriate. Other problems, such as a collusive partner relationship or intergenerational conflict, ${ }^{22}$ are addressed if needed. In the case of generalised anxiety, major depression or other psychiatric problems, test participants are advised to have additional psychological counselling sessions.

During discussion of the family communication process, the counsellor stimulates and facilitates dissemination of information among the family. Possible communication problems are identified and discussed with the counsellee. What type of information are they going to give their relatives? What kind of reactions can they get from relatives when information is given and why are these individuals reacting in that way? Why do they not want to give information to some relatives? Are family attitudes, myths or conflicts, interfering with information transmission? Special attention is paid to cognitive or emotional processes which hinder the dissemination of information within the family.

The privacy of the counsellee is an important matter during the first and second sessions. Confidentiality and privacy are complex issues in genetic counselling. ${ }^{23-25}$ On the one hand, individuals are encouraged to share genetic information with their partner, family members and close friends because it is a crucial factor in building a social support network. On the other hand, the fact that information can be misused by insurance companies or employers, and also by relatives, is discussed.

\section{Third session: decision}

After the second session, the predictive testing team discusses the predictive test request to identify possible problems or pitfalls. In the third session, relevant aspects are discussed with the test participant and a blood sample is taken for DNA analysis. Two to six weeks elapse between the final consent and availability of results. This allows test applicants to reconsider their decision to proceed. After disclosure of the predictive test result, relevant risk information and guidelines for prevention and screening are reviewed.

Medical follow-up Tested individuals are followed up by a medical specialist of their choice.

Psychological follow-up counselling This is offered 1 month, 1 year and 5 years after the test result. Special attention is paid to emotions and uncertainties of carriers and non carriers, to the impact of the test result on the relationship with the partner, the children and relatives, to the communication process in the family and to preventive or surveillance behaviour. If a woman is considering preventive mastectomy, additional counselling is provided before and after surgery.

The predictive test approach is summarised in Table1. If necessary additional counselling is offered. The partner of the test participant (or another support person) is invited to attend all sessions. Pretest sessions of male family members who apply for predictive testing are usually planned on one day, mainly because the medical risks are smaller. Male applicants know that they can reconsider their decision to proceed in the period before communication of results; additional counselling is available if necessary.

Psychological research is embedded in clinical service. During the pre and post-test period, psychometric tests and questionnaires are administered (Table2). The main aim of the pre-test psychological assessment is to establish a baseline evaluation of each individual and to predict emotional and behavioural adjustment to the test result. The assessment is also important in the context of a longitudinal study to investigate psychological consequences of genetic risk notification. The subjects are free to participate in the study.

\section{Pre-test counselling: a psychological framework}

This section is an explanation of the psychological framework which underlies the counselling that is offered in the pre-test period.

\section{Emotional support}

The importance of emotional support has been demonstrated by several studies. Lerman et $\mathrm{al}^{32}$ found that $33 \%$ of firstdegree relatives of breast cancer patients reported impairment in daily functioning due to worry about breast cancer, and $20 \%$ reported sleep disturbances. Moreover, those who were most interested in $\mathrm{HBOC}$ testing were the most anxious and distressed. ${ }^{33}$ The burden and anxiety over cancer are

Table 2 Psychometric tests

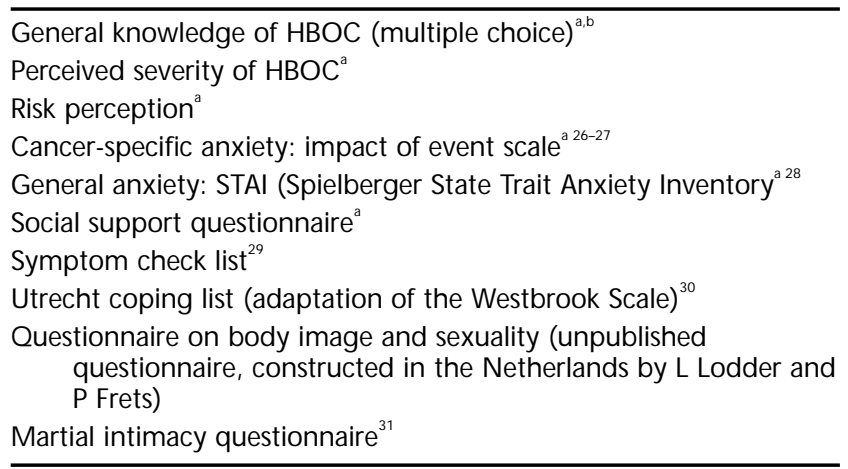

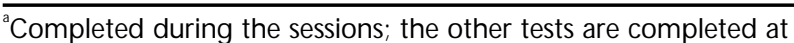
home.

${ }^{\mathrm{b}}$ Incorrect answers are detected and explained after completion of the questionnaire. 
linked to the age of the individual at the time the mother was diagnosed or died, the number of affected and/or deceased relatives and their age at diagnosis, the perceived severity and course of the cancer in these family members and the recency of newly diagnosed cases or deaths in the family. Especially daughters of breast-cancer patients, who were children or adolescents when their mother was diagnosed, are at risk of adverse emotional reactions. ${ }^{34}$ At this stage of ego and sexual development, identification with the mother and the female body is of utmost importance. Breast/ovarian cancer in the mother, combined with her own genetic susceptibility, is a threat to a daughter's body image, emotional growth, selfesteem and identity.

\section{Decision counselling}

An individual's behaviour in respect of health in a threatening genetic context depends on interaction between the individual's genetic knowledge and the process of coping with the threatening information. ${ }^{35,36}$ Coping is a dynamic process which changes over time, depending on the cognitive and subjective-emotional perception of the threatening situation and the strategies and resources for coping with the threat. An individual's experiences, beliefs, goals, values, personality and social aspects and the broader cultural context influence these perceptions.

Cognitive processing of the information Based on the information given and on personal experiences and beliefs, the participant constructs a cognitive picture of the disease. ${ }^{35}$ Considerable differences exist between individuals in the cognitive representation of $\mathrm{HBOC}$. Research has shown that some counsellees fail to acquire, understand or recall the information given during genetic counselling. ${ }^{37-39}$ Therefore, it is important to check how the test participants have interpreted the information (perception of risk, perceived severity, advantages and limitations of predictive testing, etc).

One explanation for poor understanding and/or retention of genetic information is that information about $\mathrm{HBOC}$ is very complex and difficult to explain and understand. An individual's intellectual ability, prior knowledge and experience play a crucial role in comprehension and recall of information and should be taken into account in the communication process. A leaflet with key information, which can be read at home, significantly improves understanding and recall of information. ${ }^{39,40}$

Moreover, presentation of risk information influences information processing and subsequent decision making. ${ }^{41,42}$ Risk can be presented in distinctive ways: as a percentage or a proportion, in a numerical or verbal manner, as a single figure or as a relative risk, stressing the positive or negative consequences. Presenting risk information in more than one way during genetic counselling can reduce the effect of presentation.

There are well known cognitive biases that may also play a part in processing information, for example the easier it is to imagine, recall or conceptualise an event, the more likely it will seem to arise. For example, a woman from a BRCA1/2 family, whose sister has recently been diagnosed with breast cancer, may overestimate her risk of being a gene carrier. Misunderstandings and confusions should be discussed and corrected during the counselling session.

Emotional appraisal of the situation Emotional reactions are in the first place generated by concrete personal experience and perception of the threat, rather than by verbal statements about it. ${ }^{35}$ Intense emotions may be significant barriers to information processing, decision making and surveillance behaviour. Lerman et $\mathrm{al}^{43}$ demonstrated that risk counselling did not produce improved comprehension in a group of female first-degree relatives of breast cancer patients if the women had high levels of anxiety about breast cancer. The literature has reported inconsistent findings about the relation between threat and health behaviour (such as breast cancer screening). In some studies, anxiety about cancer was associated with less undertaking of screening, ${ }^{32,44}$ whilst other research found that anxiety was unrelated to the use of health screening. ${ }^{37}$ Other studies have reported that distress over cancer was a stimulant to involvement in health practices. ${ }^{45,46}$ These contrasting figures may reflect differences in the conceptualisation or measurement of anxiety, in the nature of the behavioural outcome examined, in the health care setting and/or in the sample characteristics.

Strategies for coping Individuals react by coping differently, depending on the level of threat perceived. ${ }^{47}$ Extremely low and high levels of distress give rise to defective patterns of coping, whilst moderate levels are more likely to produce a more efficient response. This curvilinear relationship between stress level and coping reaction offers a possible explanation for the above inconsistent findings in the literature.

Coping by focusing on a problem (action plans for managing the threat, such as seeking information, visiting a general practitioner, using a screening service) and coping by focusing on an emotion (such as self-favouring evaluations, defensive pessimism, minimisation of the problem, avoidance/denial) can be either mutually destructive or facilitating. Defensive avoidance and denial are especially likely to interfere with behaviour where the focus is on the problem. ${ }^{48}$ Denial/avoidance is destructive if it undermines actions such as acquisition of information, discussion of that information with the family or surveillance behaviour. On the other hand, denial/avoidance is constructive if it reduces extreme emotional distress and allows the individual to direct his internal energy to processing information and making decisions. Especially in the early stages of coping, denial or avoidance has merits as a temporary protection against overwhelming feelings, but in the long run it can undermine actions focused on problems. Moreover, when denial is partial or minimal, it does not necessarily undermine simultaneous coping by focusing on problems. 
Subjective perception that time is of the essence might lead to hypervigilance: impulsive reactions, reduced memory span and less reflection on the implications of a decision. This may result in extreme surveillance behaviour, such as daily self-examination of the breasts, or a poorly informed decision to perform a bilateral mastectomy. ${ }^{49}$

Resources for coping Evaluation and enhancement of the test participant's coping resources is another essential component of decision counselling. Familial disease and genetic risk can undermine self-esteem and identity. This is potentially more serious in daughters of breast-cancer patients, who were in adolescents or children when their mother's condition was diagnosed. ${ }^{34}$ Self-esteem and feelings of personal control prove to be associated with an increase in adaptive coping such as information seeking and problem solving. Lack of faith in one's own ability to cope proves to be associated with negative reactions, such as feeling hopeless or depressed and giving up..$^{50,51}$

\section{Guidance and support of the damily communication process}

Another important aim of HBOC psychological counselling is the guidance and support of the family communication process on the subject of hereditary cancer and discussion of theimplication s of withholding information. ${ }^{17,18,52}$ We are of the opinion that it is the moral responsibility of family members to inform other relatives about the genetic risks in the family, and it is the geneticist's task to remind the counsellee of this responsibility and to stimulate and facilitate the dissemination of such information within the family. We agree with the ethical view that medical confidentiality should not be broken by clinicians when family members do not wish their relatives to be informed about the genetic disease in the family. ${ }^{53,54}$ Richards and $\mathrm{Green}^{54}$ have argued that individuals may have good reason not to pass on information to relatives and that to intervene might disrupt family relationships. This contrasts with the view ${ }^{55}$ that medical confidentiality might be broken under certain conditions.

Ways of handling emotion may complicate discussion of genetic information in the family. Relatives develop their own ways of dealing with the risk. Some refuse to discuss any aspect of the situation, whilst others share their experience and feelings with relatives. Especially individuals who want to tell the family in order to control the threat and their own grief, or who see themselves as the conveyor of information to the family may beat risk and may need additional support and guidance in such a role. ${ }^{18}$ Some families develop family secrets and myths about $\mathrm{HBOC}$ and its inheritance. An example of such phenomena is patient preselection: ${ }^{56}$ a sister or brother is pre-selected by the other siblings to be the potential patient, so that they have the illusion that their own risk has been reduced. Processes of identification are used to support the illusion: behavioural or physical resemblances between the preselected person and the affected parent are highlighted, which reinforces the pre-selection. Such pretending can be stronger than factual information. An atmosphere of secrets and taboos may thwart the communication process and the social support sought in the family and may even result in conflicts and family rifts.

Julian-Reynier et $\mathrm{al}^{57}$ reported that about $14 \%$ of 161 patients who had been asked to contact their relatives, firmly refused to do so, mainly because of problematic familial relationships. Other significant barriers to informing family members are guilt, shame, anxiety or depression. Green et $\mathrm{al}^{52}$ found that 'communication, both obtaining and giving information, was impeded by adoption, divorce and remarriage, family rifts, and large age gaps between siblings'. Moreover, $\mathrm{HBOC}$ is generally perceived as merely a woman's problem. ${ }^{52,58}$ This, in combination with the taboo surrounding $\mathrm{HBOC}$, results in neglect of the male members in the family communication process. It also prevents women bringing their partners to the counselling sessions.

The discussion about family communication is complex and delicate because of the interplay of individual and family beliefs, attitudes, imaginings and intense emotions. Moreover, several conflicting values play a part in dissemination of information: the right to know, the right not to know, autonomy, privacy and solidarity. ${ }^{23-25}$

\section{Discussion}

In this paper, we have described the multidisciplinary predictive testing service for $\mathrm{HBOC}$ in Leuven, with special attention to psychological and decision counselling and the underlying psychological concepts. Notwithstanding essential differences in types of disease, the predictive test approach for Huntington Disease (HD) $)^{59,60}$ and experience with other neurogenetic diseases have been a valuable foundation and starting point for developing predictive testing for HBOC. Unlike HD, this is potentially preventable and can be treated if detected early, although the efficacy of early detection and prevention is uncertain. This results in a need for more counselling and recommendations for surveillance behaviour. The pre-test sessions for $\mathrm{HBOC}$ take longer than for HD, because $\mathrm{HBOC}$ is associated with greater complexity and uncertainty. Moreover, initial research suggests that people who are most interested in $\mathrm{HBOC}$ testing are the most anxious and distressed. ${ }^{33}$ This contrasts with the HD findings that predictive test applicants for HD were a selfselected group with significantly higher mean ego-strength and with significantly better means of coping than the general population. ${ }^{60}$ Another major difference from HD is that non-carriers of the BRCA1/2 mutation in families with the mutation remain at the general population level of risk of cancer. Lynch et al $^{61}$ suggested that some women with a favourable result might continue to worry about developing cancer. Because of the far-reaching medical and psychological consequences of predictive testing for $\mathrm{HBOC}$, we offer the applicants a combination of information-oriented and 
psychological counselling. Both are prerequisites for free informed decision making. We fully agree that the decision to undergo predictive testing '... should be approached as a multi-step process, and those considering genetic testing must be given every chance to rethink and confirm their final decision'. ${ }^{19}$ It is important that people have sufficient time to reflect between receiving the first information on $\mathrm{HBOC}$ and their decision to take the test. Although it is not considered a standard of care, ${ }^{19,20}$ we offer the applicants a psychological and decision counselling session with a psychologist, and if necessary a psychiatrist, before their final decision. Some (published) test protocols ${ }^{16,18}$ also include an additional session with a psychologist.

A specialist multidisciplinary team is required to provide extensive pre- and post-test counselling for HBOC. In our opinion, this team should at least include a clinical geneticist, a psychologist or genetic nurse and relevant specialist physicians (oncology, surgery, gynaecology, psychiatry). The specific organisation of the genetic testing service in a country depends on several factors, such as its health care system and financial resources. It is of the utmost importance that sufficient financial resources are allocated to genetic cancer services so that predictive testing can be offered in a multidisciplinary context.

At present, many questions about $\mathrm{HBOC}$ remain unsolvedthe impact of genetic testing and efficacy of education, counselling and preventive measures. Further research is needed to reduce these uncertainties. Genetic protocols have been developed all over the world in the form of research projects to eval uate the efficacy of genetic testing in reducing morbidity and mortality from HBOC. Longitudinal studies to evaluate the immediate and long-term psychological impact of genetic testing are also of the utmost importance. This requires sufficient knowledge of methodology for qualitative and quantitative psychological research. Psychologists working in cancer genetics must combine research and psychological counselling skills, and have sufficient insight into psychological and genetic concepts.

\section{Acknowledgements}

M. Welkenhuysen's contribution is part of her research activities in the context of the project 'The challenge of predictive testing for late onset diseases' of the Flanders Interuniversity Institute for Biotechnology (VIB).

\section{References}

1 American Cancer Society: Cancer Facts and Figures. American Cancer Society: Atlanta, 1998; 4.

2 Freilich G: Breast cancer: a personal and public concern. Europa Donna News 1997; 1-2.

3 King MC, Rowell S, Love SM: Inherited breast and ovarian cancer. What are the risks? What are the choices? JAMA 1993; 269: 1975-1980.

4 Miki Y, Swensen J, Shattuck-Eidens D et al: A strong candidate for the breast and ovarian cancer susceptibility gene BRCA1. Science 1994; 266: 66-71.
5 Wooster R, Bignell G, Lancaster J et al: Identification of the breast cancer susceptibility gene BRCA2. Nature 1995; 378: 789-792.

6 Easton DF, Steele L, Fields P et al: Cancer risks in two large breast cancer families linked to BRCA2 on chromosome13q12-13. Am J Hum Genet 1997; 61: 120-128.

7 Blackwood MA, Weber BL: BRCA1 and BRCA2: from molecular genetics to clinical medicine. J Clin Oncol 1998; 16: 1969-1977.

8 Ford D, Easton DF, Stratton M et al: Genetic heterogeneity and penetrance analysis of the BRCA1 and BRCA2 genes in breast cancer families. Am J Hum Genet 1998; 62: 676-689.

9 Devilee P: BRCA1 and BRCA2 testing: weighing the demand against the benefits. Am J Hum Genet 1999; 64: 943-948.

10 Schover LR: The impact of breast cancer on sexuality, body image and intimate relationships. Cancer J for Clinicians 1991; 41: 112-120.

11 Payne DK, Sullivan MD, Massie MJ: Women's psychological reactions to breast cancer. Sem Oncol 1996; 23: 89-97.

12 Burke W, Daly M, Garber J et al for the Cancer Genetics Study Consortium: Recommendations for follow-up care of individuals with an inherited predisposition to cancer II. BRCA1 and BRCA2. JAMA 1997; 277: 997-1003.

13 Hoskins KF, Stopfer JE, Calzone KA et al: Assessment and counseling for women with a family history of breast cancer. A guide for clinicians. JAMA 1995; 273: 577-585.

14 Hartmann LC, Schaid DJ, Woods JE et al: Efficacy of bilateral prophylactic mastectomy in women with a family history of breast cancer. N Engl J Med 1999; 340: 77-84.

15 Biesecker BB, Boehnke M, Calzone K et al: Genetic counseling for families with inherited susceptibility to breast and ovarian cancer. JAMA 1993; 269: 1970-1974.

16 Botkin JR, Croyle RT, Smith KR et al: A model protocol for evaluating the behavioral and psychosocial effects of BRCA1 testing. J Natl Cancer Inst 1996; 88: 872-882.

17 Lerman C, Croyle R: Emotional and behavioral responses to genetic testing for susceptibility to cancer. Oncology 1996; 10: 191-195, 199.

18 Dudok de Wit AC, Tibben A, Frets PG et al: BRCA1 in the family: a case description of the psychological implications. Am J M ed Gen 1997; 71: 63-71.

19 Geller G, Botkin JR, Green MJ et al: Genetic testing for susceptibility to adult-onset cancer. The process and content of informed consent. JAMA 1997; 277: 1467-1474.

20 Advisory Committee on Genetic Testing: Genetic Testing for Late Disorders. London, Health Departments of the United Kingdom, 1998.

21 Huys J, Evers-Kiebooms G, d'Ydewalle G: Decision making in the context of genetic risk: the use of scenarios. In: Evers-Kiebooms G, Fryns JP, Cassiman JJ, Van den Berghe H (eds). Psychosocial Aspects of Genetic Counseling. March of Dimes, Birth Defects Association: 1992, 28: 17-20.

22 Demyttenaere K, Evers-Kiebooms G, Decruyenaere M: Pitfalls in counseling for predictive testing in Huntington disease. In: EversKiebooms G, Fryns JP, Cassiman JJ, Van den Berghe H. Psychosocial Aspects of Genetic Counseling. March of Dimes, Birth Defects Association: 1992, 28: 105-112.

23 De Wert G: Ethics of predictive DNA-testing for hereditary breast and ovarian cancer. Patient Educ Couns 1998; 35: 43-52.

24 Benkendorf JL, Reutenauer JE, Hughes CA et al: Patients' attitudes about autonomy and confidentiality in genetic testing for breastovarian cancer susceptibility. Am J Med Gen 1997; 73: 296-303.

25 Boddington P: Confidentiality in genetic counselling. In: Clarke A (ed.). Genetic Counselling. Practice and Principles. Routledge: London, New York, 1994; pp 223-240.

26 Horowitz MJ, Wilner N, Alvarez W: Impact of event scale: a measure of subjective stress. Psychosom Med 1979; 41: 209-218.

27 Tibben A, Duivenvoorden HJ, Niermeijer MF, Vegter-van der Vlis M, Roos RAC, Verhage F: Psychological effects of presymptomatic DNA testing for Huntington's disease in the Dutch program. Psychosom Med 1994; 56: 526-532. 
28 Spielberger CD, Gorsuch RL, Lushene RE: Manual for the State Trait Anxiety Inventory. Consulting Psychologists' Tests: Palo Alto, 1970.

29 Derogatis LR: Symptom Check List: Administration, Scoring and Procedures Manual for the Revised Version. Johns Hopkins, University School of Medicine: Baltimore, 1977.

30 Westbrook MT: A classification of coping behavior based on multidimensional scaling of similarity rating. J Clin Psych 1979; 35: 407-410.

31 Van den Broucke S, Vandereycken W, Vertommen H: Marital intimacy: conceptualization and assessment. Clin Psych Rev 1995; 15: $217-233$.

32 Lerman C, Daly M, Sands C et al: Mammography adherence and psychological distress among women at risk for breast cancer. J Natl Cancer Inst 1993; 85: 1074-1080.

33 Lerman C, Daly M, Masny A, Balshem A: Attitudes about genetic testing for breast-ovarian cancer susceptibility. J Clin Oncol 1994; 12: 843-850.

34 Wellisch DK, Gritz ER, Schain W, Wang H, Siau J: Psychological functioning of daughters of breast cancer patients. Part II. Characterizing the distressed daughter of the breast cancer patient. Psychomatics 1992; 33: 171-179.

35 Leventhal H, Safer MA, Panagis DM: The impact of communications on the self-regulation of health beliefs, decisions and behavior. Health Educ Quart 1983; 10: 3-29.

36 Decruyenaere M, Evers-Kiebooms G, Denayer L, Welkenhuysen $\mathrm{M}$ : Uptake and impact of carrier testing for cystic fibrosis. A review and a theoretical framework about the role of knowledge, health beliefs and coping. Comm Gen 1998; 1: 23-35.

37 Lloyd S, Watson M, Waites B et al: Familial breast cancer: a controlled study of risk perception, psychological morbidity and health beliefs in women attending for genetic counselling. $\mathrm{Br}$ J Cancer 1996; 74: 482-487.

38 Watson M, Duvivier V, Walsh MW et al: Family history of breast cancer: what do women understand and recall about genetic risk? J Med Gen 1998; 35: 731-738.

39 Evans DGR, Blair V, Greenhalgh R, Hopwood P, Howell A: The impact of genetic counselling on risk perception in women with a family history of breast cancer. Br J Cancer 1994; 70: 934-938.

40 Cho MK, Arruda M, Holtzman NA: Educational material about genetic tests: does it provide key information for patients and practitioners? Am J Med Gen 1997; 73: 314-320.

41 Tversky A, Kahneman D: The framing of decisions and the psychology of choice. Science 1981; 211: 453-458.

42 Shiloh S, Sagi M: Effect of framing on the perception of genetic recurrence risks. Am J Med Genet 1989; 33: 130-135.

43 Lerman C, Lustbader E, Rimer B et al: Effects of individualized breast cancer risk counseling: a randomized trial. J Natl Cancer Inst 1995; 87: 286-292.

44 Kash KM, Holland JC, Halper MS, Miller DG: Psychological distress and surveillance behaviors of women with a family of breast cancer. J Natl Cancer Inst 1992; 84: 24-30.
45 Lerman C, Schwartz MD, Lin TH, Hughes C, Narod S, Lynch HT: The influence of psychological distress on use of genetic testing for cancer risk. J Consult Clin Psychol 1997; 65: 414-420.

46 McCaul KD, Reid PA, Rathge RW, Martinson B: Does concern about breast cancer inhibit or promote breast cancer screening? Basic Appl Soc Psychol 1996; 18: 183-194.

47 Mann L: Stress, affect, and risk taking. In: YatesJF (ed.). Risk-taking Behavior. Wiley: New York, 1992, pp 201-230.

48 Lazarus RS, Folkman S: Stress, Appraisal and Coping. Springer: New York, 1984.

49 Lerman C, Kash K, Stefanek M: Younger women at increased risk for breast cancer: psychological well-being, perceived risk and surveillance behaviour. Natl Cancer Inst Monogr 1994; 16: 171-176.

50 Rippetoe PA, Rogers RW: Effects of components of protectionmotivation theory on adaptive and maladaptive coping with health threat. J Pers Soc Psych 1987; 52: 596-604.

51 Schwarzer R: Self-efficacy in the adoption and maintenance of health behaviors: theoretical approaches and a new model. In: Schwarzer R (ed.). Self-efficacy: Thought Control of Action. Hemisphere: Washington, 1992; pp 217-243.

52 Green J, Richards M, Murton F, Statham H, Hallowell N: Family communication and genetic counseling: the case of hereditary breast and ovarian cancer. J Gen Couns 1997; 6: 45-60.

53 House of Commons Science and Technology Committee: Human Genetics: The Science and its Consequences. HMSO: London, 1995, vol. 2

54 Richards M, Green J: Attitudes towards prenatal screening for fetal abnormality and detection of carriers of genetic disease: a discussion paper. J Reprod Infant Psychol 1993; 11: 49-59.

55 Nuffield Council on Bioethics: Genetic Screening: Ethical Issues. Nuffield Foundation: London, 1993.

56 Kessler S, Bloch M: Social system responses to Huntington Disease. Family Processes 1989; 28: 59-68.

57 Julian-Reynier $C$, Elsinger $F$, Vennin $P$ et al: Attitudes towards cancer predictive testing and transmission of information to the family. J Med Genet 1996; 33: 731-736.

58 Lerman C, Narod S, Schulman K et al: BRCA1 testing in families with hereditary breast-ovarian cancer. A prospective study of patient decision making and outcomes. JAMA 1996; 275: 1885-1892.

59 Decruyenaere M, Evers-Kiebooms G, Boogaerts A et al: Nonparticipation in predictive testing for Huntington's disease: individual decision-making, personality and avoidant behaviour in the family. Eur J Hum Gen 1997; 5: 351-363.

60 Evers-Kiebooms G, Decruyenaere M: Predictive testing for Huntington's disease: a challenge for persons at risk and for professionals. Patient Educ Counsel 1998; 35: 15-26.

61 Lynch HT, Watson P, Conway TA et al: DNA screening for breast/ ovarian cancer susceptibility on linked markers: a family study. Arch Intern Med 1993; 153: 1979-1987. 